\title{
Nucleo-cytoplasmic transport of TDP-43 studied in real time: impaired microglia function leads to axonal spreading of TDP-43 in degenerating motor neurons
}

\author{
Adam J. Svahn ${ }^{1} \cdot$ Emily K. Don ${ }^{1} \cdot$ Andrew P. Badrock ${ }^{1,2} \cdot$ Nicholas J. Cole $^{1} \cdot$ Manuel B. Graeber $^{3} \cdot$ Justin J. Yerbury ${ }^{4}$. \\ Roger Chung ${ }^{1} \cdot$ Marco Morsch $^{1}$
}

Received: 1 December 2017 / Revised: 9 June 2018 / Accepted: 9 June 2018 / Published online: 25 June 2018

(c) The Author(s) 2018

\begin{abstract}
Transactivating DNA-binding protein-43 (TDP-43) deposits represent a typical finding in almost all ALS patients, more than half of FTLD patients and patients with several other neurodegenerative disorders. It appears that perturbation of nucleo-cytoplasmic transport is an important event in these conditions but the mechanistic role and the fate of TDP-43 during neuronal degeneration remain elusive. We have developed an experimental system for visualising the perturbed nucleocytoplasmic transport of neuronal TDP-43 at the single-cell level in vivo using zebrafish spinal cord. This approach enabled us to image TDP-43-expressing motor neurons before and after experimental initiation of cell death. We report the formation of mobile TDP-43 deposits within degenerating motor neurons, which are normally phagocytosed by microglia. However, when microglial cells were depleted, injury-induced motor neuron degeneration follows a characteristic process that includes TDP-43 redistribution into the cytoplasm, axon and extracellular space. This is the first demonstration of perturbed TDP-43 nucleocytoplasmic transport in vivo, and suggests that impairment in microglial phagocytosis of dying neurons may contribute towards the formation of pathological TDP-43 presentations in ALS and FTLD.
\end{abstract}

Keywords Amyotrophic lateral sclerosis (ALS) · Motor neuron disease (MND) · Neurodegeneration · Microglia · TDP-43 · Pathological spreading $\cdot$ Zebrafish

Electronic supplementary material The online version of this article (https://doi.org/10.1007/s00401-018-1875-2) contains supplementary material, which is available to authorized users.

Roger Chung

roger.chung@mq.edu.au

$\triangle$ Marco Morsch

marco.morsch@mq.edu.au

1 Department of Biomedical Sciences, Faculty of Medicine and Health Sciences, Centre for Motor Neuron Disease Research, Macquarie University, Sydney, NSW, Australia

2 Faculty of Life Sciences, The University of Manchester, Manchester, UK

3 Brain Tumor Research Laboratories, Brain and Mind Centre, The University of Sydney, Sydney, NSW, Australia

4 Faculty of Science, Medicine and Health, School of Biological Sciences, University of Wollongong, Wollongong, NSW, Australia

\section{Introduction}

Pathological deposition of protein aggregates characterises a large group of neurodegenerative diseases in which the key event is considered to be either the malformation of a key protein, or the failing of a crucial metabolic cascade, leading to the generation of a pathological proteinaceous agent that can self-propagate and result in gain- or loss-of-function progressing toward cell death [38].

An aggregating proteinopathy involving the TAR DNAbinding protein (TDP-43) provides a molecular link between two progressive neurodegenerative diseases: amyotrophic lateral sclerosis (ALS) of the motor cortex, brainstem and spinal cord, and frontotemporal lobar degeneration (FTLD) of the frontal, insular, and temporal cortex (non-SOD1 ALS and non-tau FTLD, termed ALS-FTLD; [3, 13, 15, 22, 43]).

In biochemical and cell culture models, TDP-43 has been identified as spontaneously aggregation prone $[1,27]$. This propensity has been localised to a low-complexity domain in the C-terminal region that may play a role in RNA binding, 
granule formation, and/or liquid-liquid phase separation to subserve transcription dynamics and mRNA transport [6, $12,32,34,55,56]$. It is hypothesised that inherited or spontaneous mutation of the encoding gene, TARDBP, or of an interacting partner, upsets the balance between aggregation and dissolution of TDP-43 [14, 71], which may be differentially regulated under changing conditions, including during the cellular stress/death response [7, 30].

TDP-43 also appears to display self-propagating behaviour. Feiler et al. [21] found that naive cultured mouse neurons will internalise tagged, oligomerized TDP-43 from the culture medium of transfected neurons. This was mediated by the packaging of TDP-43 into microvesicles or exosomes, which were more effective at transmission than free protein. Linking this phenomenon to clinical observations, when cell culture models were seeded with phosphorylated TDP- $43^{\text {+ve }}$ insoluble fractions from ALS and FTLD patient brain or spinal cord, there was a significant increase in intracellular endogenous TDP-43 aggregation and subsequent cell death $[44,57]$. To follow on from this we examined how motor neuron injury and subsequent degeneration mobilises TDP43 in vivo and may contribute to pathogenicity in ALS.

We have developed an in vivo transgenic model to visualise subcellular compartments of individual motor neurons in zebrafish spinal cord. Using this new model, we have expressed fluorophore-tagged human TDP-43 within individual spinal motor neurons to observe the intraneuronal localisation of TDP-43 over time. After confirming that the subcellular localisation of TDP-43 is the same in zebrafish and human, we discovered in vivo that TDP-43 concentrated in highly dynamic nuclear granules with droplet-like properties. By application of a cell-specific UV injury, we were able to induce neuronal degeneration, within which the fate of TDP-43 could be precisely followed. We found that motor neurons underwent a stereotyped neurodegenerative process with structural changes closely mirroring those of degenerating neurons in human tissue. We further report upon live-imaging evidence for different pathways of TDP43 release and distribution; as aggregated fragments, diffuse in cytoplasm, as a component of pyknotic or karryhorexic nuclear fragmentation, anterograde axonal diffusion or as a component of microglial uptake.

\section{Materials and methods}

\section{Zebrafish care}

Zebrafish (Danio rerio) were maintained under standard conditions [65]. Experiments were conducted under Macquarie University Animal Ethics and Biosafety approvals (2012/050 and 2015/033; 5201401007). Larvae were raised in $\mathrm{E} 3$ medium at $28^{\circ} \mathrm{C}$ on a 14:10 light:dark cycle.
1-Phenyl-2-thiourea (PTU) was added to the E3 medium at $24 \mathrm{hpf}$ at $0.005 \%$ to inhibit pigmentation. All experiments in this study were conducted at 3-5 days post-fertilisation (dpf).

\section{Transgenes}

Tg(-3mnxl:kalTA4-4xnrUAS-E1b-H2B-mCerulean3-P2A$m K O 2-C A A X)$ (MQ13) was generated using recombined p5E-3mnx1 [40], pME: kalTA4-4xnrUAS-E1b, p3E-H2BmCerulean3-P2A-mKOFP2-CAAX [17], and pTol2pA2 [33]. The pME:kalTA4-4xnrUAS-E1b construct was generated from PCR amplification of EcoRI- and Xho1-flanked kalTA4, and Xho1- and Sal1-flanked 4xnrUAS sequences from pME:kalTA4 and pME:4xnrUAS vectors, respectively (both vectors were a kind gift from the Parton Lab, University of Queensland). A Sal1- and Spe1-flanked E1b minimal promoter was added to the $3^{\prime}$ end and the construct subcloned into a lab derived pDONR 221 (Invitrogen) vector with EcoRI and Spe 1 sites. The codonoptimised H2B-mCerulean3-P2A-mKOFP2-CAAX sequence was ordered from GeneArt and recombined into pDONRP2R-P3 (Invitrogen) to create the p3E-H2B-mCerulean3-P2A-mKOFP2-CAAX [17]. It incorporated a nuclear-localised mCerulean 3 fluorophore and a membranelocalised mKOFP2 (mKO2) fluorophore expressed in motor neurons.

Tg (-3mnxl:eGFP-HsaTDP-43 ${ }^{W T}$ ) was generated using recombined p5E-3mnx1 (\#74632) [40], pME-EGFP [33], p3E-HsaTDP-43 and pTol2pA2 [33]. The p3E-HsaTDP-43 was generated by subcloning a BamHI-Spe 1 -flanked gene string encoding HsaTDP-43 (GeneArt) into the BamHI-Spe 1 sites of p3E-MCS (\#75174) [17].

Transgenic lines were generated by co-injection of the Tol2-flanked constructs and transposase [28].

\section{PU.1 (spi1b) morpholino}

The PU.1 morpholino and a mismatch control used in this study were the same as those of Rhodes et al. [50], obtained from Gene Tools. Injections consisted of a $2 \mathrm{ng} / \mathrm{nl}$ concentration of either active or mismatch morpholino in a 2-nl droplet calibrated by micrometre. Immediately after injections, dishes containing equal numbers of either active or mismatch injected larvae or uninjected siblings were coded by a third party and all following analyses were conducted blind to the injection condition. At 3 and $5 \mathrm{dpf}$, larvae were screened for developmental abnormalities and for the presence of any mCherry-CAAX fluorophore expression, indicating the presence of mpeg1 expressing monocytes. 
PU.1 (spilb)-targeted active MO: 5'-GATATACTGATA CTCCATTGGTGGT-3'

PU.1 (spilb) mismatch MO: 5'-GATAAACTGTTACTC GATTGCTGGT-3'

\section{Notes on morpholino and zebrafish PU.1 orthologues spi1a/b}

An in silico analysis showed that for the two zebrafish orthologues of PU.1, spila and spilb, the morpholino above contains a matching sequence only for spilb (D. rerio, GRCz10). Given the efficacy of the morpholino in this and previous studies [25, 48-50] knockdown of spilb appears sufficient to induce primitive monocyte lineage inhibition in the zebrafish.

\section{Imaging and UV injury induction}

Imaging was conducted on a Leica SP5 confocal microscope. mTagBFP was excited by 405-nm laser diode, which was also used at higher power to induce UV injury [41]. eGFP was excited by an argon laser at $488 \mathrm{~nm}$. mKO2-CAAX and mCherry-CAAX were excited by a Leica white-light laser at 552 and 587 nm, respectively. Imaging for Fig. 2 and Online Resources 1 and 6 was conducted with an $8 \mathrm{kHz}$ Leica resonance scanner. Objectives used were a Leica 40x HCX APO L U-V-I water immersion and a Leica $63 \mathrm{X}$ HC APO U-V-I CS2 water immersion.

Imaging processing was conducted in Image $(1.51 \mathrm{n})$. Deconvolution was applied for Figs. 1, 2, 4, 5, 6 and 7. Point spread functions were generated by the Richards and Wolf algorithm [51] as implemented in the PSF generator plugin for ImageJ [31]. Richardson-Lucy deconvolution was carried out in the DeconvolutionLab plugin for ImageJ [53]. A mean filter of radius 1 was applied to Figs. 4 and 6.

\section{D volume analysis of TDP-43 nuclear/cytoplasm ratio}

The ratio of nuclear to cytoplasmic eGFP-TDP $43^{\mathrm{WT}}$ over the 3D neuron volume was derived by first establishing a separation of voxels containing eGFP-TDP43 ${ }^{\mathrm{WT}}$ alone (cytoplasm) or both eGFP-TDP43 ${ }^{\mathrm{WT}}$ and H2B-mCerulean3 (nucleus) using a custom macro in ImageJ. Fluorescence grey value of each voxel was regarded as an indication of fluorophore concentration and the voxel grey value was summed over each set. The neurons used in this analysis were imaged from the same crossing and with identical microscope excitation and collection settings.

\section{D volume analysis of TDP-43 accumulations}

The volume measurements of the nuclear accumulations of eGFP-TDP43 ${ }^{\mathrm{WT}}$ were derived by automatic $3 \mathrm{D}$ object recognition in ImageJ. $205-\mu \mathrm{m} \times 51-\mu \mathrm{m} \times 24-\mu \mathrm{m}$ z-stacks were acquired in the spinal cord of three larvae expressing mnx 1-driven eGFP-TDP $43^{\mathrm{WT}}$ from the same crossing. Object counting was conducted with the Object Counter3D plugin in ImageJ (plugin authors are F. Cordelières and J. Jackson. The plugin is available at http://rsbweb.nih.gov/ij/ plugins/track/objects.html).

\section{Axonal eGFP localisation}

For the analysis of eGFP in the axon before and after UV injury of Fig. 7 and Online Resource 9, the Simple Neurite Tracer plugin for ImageJ (v3.1.3, [36]) was used to generate a neurite vector and gather individual segment and whole neurite fluorescence intensity measures.

For the baseline of eGFP signal present in uninjured motor neuron axons of Supplementary Figure 4 (Online Resource 10), an 8- $\mu \mathrm{m}$ segmented line was drawn along the axon path from the hillock in Z-projected stacks, as visualised by the mKO2-CAAX fluorophore. The mean grey value was measured in the voxels falling on this line for both mKO2-CAAX and eGFP. To demonstrate that any eGFP signal was not lost to a process of background subtraction, we sampled two 8- $\mu$ m lines in regions of the same image without a positively expressing cell to determine the background levels for each fluorophore in each image. These background values were averaged and reported to give the background value used for comparison to the axon path. The neurons used in this analysis were imaged from the same crossing and with identical microscope excitation and collection settings.

\section{Statistical analysis}

The software R (3.3.2) was used for statistical analyses. Differences between the means were evaluated using ANOVAs and post hoc Tukey tests. For all statistical tests, significance was taken as $P<0.05$. Unless otherwise indicated, data values are presented as the mean \pm standard error of the mean (SEM). Graphs were generated in R (3.3.2) and Microsoft Excel 2016. 


\section{Results}

\section{Visualising the distribution of TDP-43 within spinal motor neurons using sub-compartment-specific reporters}

To visualise and temporally monitor the process of motor neuron degeneration and the subsequent fate of intraneuronal TDP-43 in the living spinal cord, we developed a multitransgenic approach in zebrafish. Expression of fluorophore reporters was driven by the mnxl promoter, previously described in primary motor neurons and interneurons in the zebrafish spinal cord [40, 42, 68]. Fluorophores were targeted towards specific subcellular compartments through the use of specific peptide tags, for membrane ( $\mathrm{mKO} 2-\mathrm{CAAX}$ ), nucleus (H2B-mCerulean3) and cytoplasm (mTagBFP) (Figs. 1, 2). Human wildtype TDP-43 (TDP-43 ${ }^{\mathrm{WT}}$ ) was visualised with an eGFP tag (eGFP-TDP43 ${ }^{\mathrm{WT}}$, Fig. 1biv).

In the motor neurons of the zebrafish spinal cord, eGFPTDP43 ${ }^{\mathrm{WT}}$ was observed to be strongly concentrated in the nucleus while relatively diffuse in the cytosol (Figs. 1biv, 2). This is in keeping with qualitative observations in human tissue section [43, 61], mouse tissue [39, 54] and cell culture models $[4,64]$. To quantify this distribution, we assayed the relative distribution of eGFP-TDP43 ${ }^{\mathrm{WT}}$ across the nucleus and cytoplasm over the entire cell body as a 3D volume, as determined by comparison with the co-expressed nuclear marker, H2B-mCerulean3 (see "Materials and methods"). We found that $78.2 \%$ of eGFP-TDP $43^{\mathrm{WT}}$ localised to the nucleus $( \pm 4.6 \%, n=12$ neurons in 4 larvae). This percentage is in line with a $\sim 85 \%$ nuclear localisation reported previously using western blot quantitation of nuclear/cytoplasmic fractions from cultured hippocampal neurons [64].

\section{Visualisation of dynamic TDP-43 granula in the nucleus of spinal motor neurons}

The nucleus contained eGFP-TDP43 ${ }^{\mathrm{WT}}$ in the form of discrete fluorescent "granula". Automatic 3D object analysis of the TDP-43 aggregates revealed a volume range of $0.023-5.7 \mu \mathrm{m}^{3}$, with $83 \%$ falling in the range of $0.023-0.048 \mu^{3}$ (132 accumulations in three larvae, Supplementary Fig. 1 (Online Resource 10)). Live imaging revealed that these TDP-43 granula were not stationary but showed highly dynamic movements within the nucleus (Online Resource 1). Using high-frequency image acquisition ( $8 \mathrm{kHz}$ resonance scanner, image every $50 \mathrm{~s})$, droplet-like interactions between the accumulations could be observed (Fig. 2 and Online Resource 1). These may be indicative of TDP-43 incorporation in nuclear phase-separation compartmentalisation $[60,70]$.

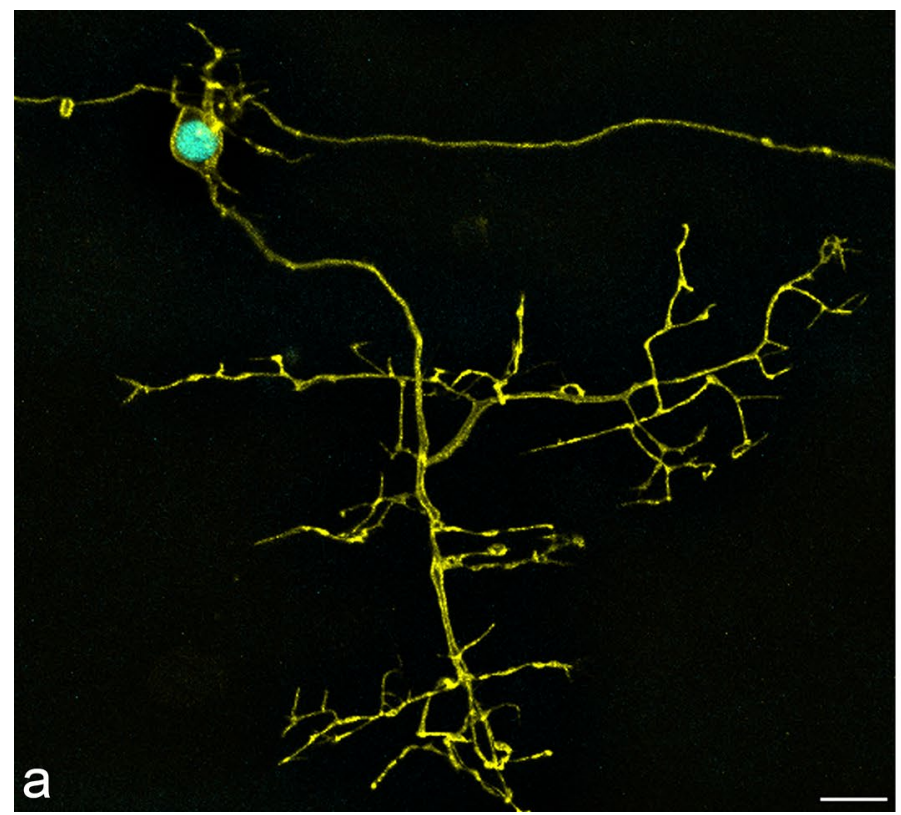

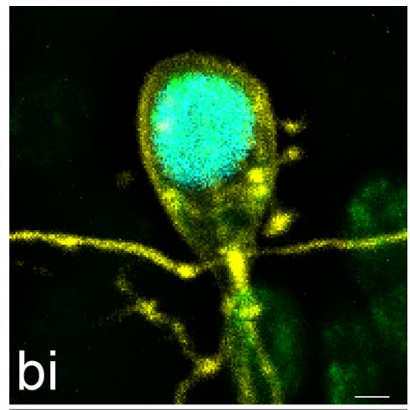
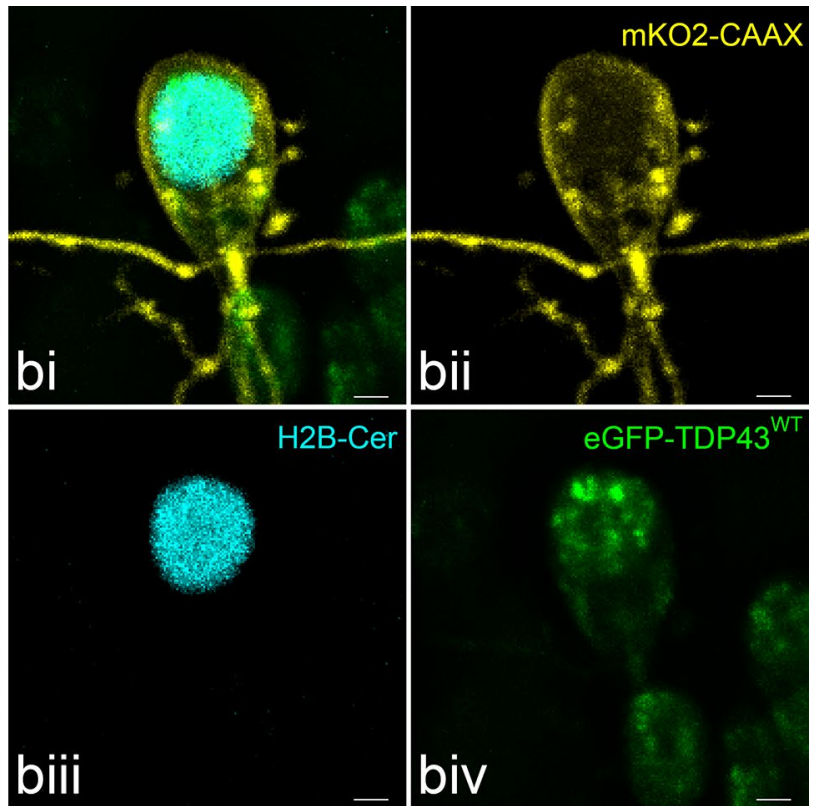

Fig. 1 Fluorescent primary motor neurons in the zebrafish spinal cord at $3 \mathrm{dpf}$. a Maximum intensity projection of a z-stack of a motor neuron revealing the complete axonal arbour (yellow) projecting into and around the myotome (not shown). At the cell body the spindly dendritic arbour can also be observed. The nucleus is visualised in
mCerulean3 (cyan). Traversing the image is the axon of a spinal interneuron. Scale $=10 \mu \mathrm{m}$. b A separate fluorescent motor neuron (bi), demonstrating the mnx1-driven membrane-bound $\mathrm{mKO} 2$ CAAX (yellow, bii), nuclear H2B-mCerulean3 (cyan, biii) and HsaTDP43 ${ }^{\text {WT }}$-linked eGFP (green, biv). Scale $=2 \mu \mathrm{m}$ 

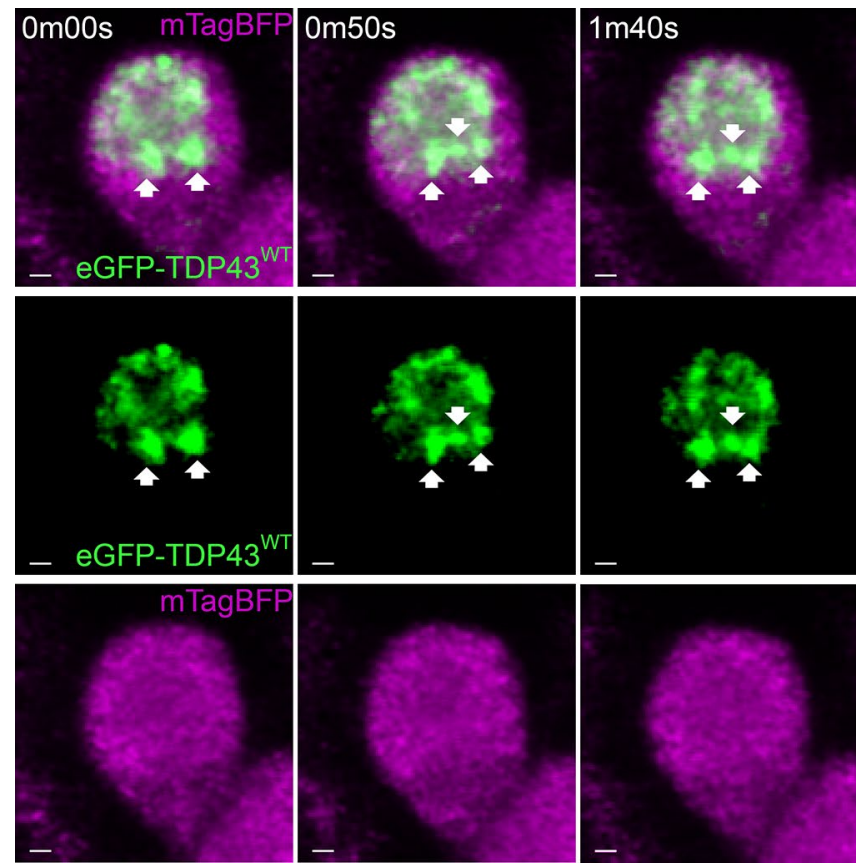

Fig. 2 Nuclear TDP-43 accumulations are highly motile. Fast resonance scan of a motor neuron cell body with cytoplasmic mTagBFP (magenta) and nuclear eGFP-TDP43 ${ }^{\mathrm{WT}}$ (green) revealed that these TDP-43 accumulations rapidly dissociate and coalesce. The full time-

\section{Targeted UV-mediated injury in motor neurons induced a local microglial response including phagocytosis of intracellular TDP-43}

We have previously demonstrated that application of a UV laser $(405 \mathrm{~nm})$ can selectively induce injury and cell death in zebrafish motor neurons in vivo [40, 41]. The UV laser beam can be focused to a narrow column of subcellular width. Accordingly, as shown in experiments with spinal cord motor neurons expressing the photoconvertible Kaede fluorophore, a single motor neuron can be precisely targeted [40]. To further characterise the UV-mediated cellular damage in this in vivo model, we examined the bleaching curves in the regions immediately neighbouring the laser beam. Bleaching did occur around the target column; however, it was attenuated by $50 \%$ within $10 \mu \mathrm{m}$ (approx. one cell width) and nearly 80\% within $20 \mu \mathrm{m}$ [Supplementary Fig. 2 (Online Resource 10)]. This steep power attenuation in the immediate surroundings of the laser beam supports the view that our method can be used to inflict very precise subcellular damage to selectively induce degeneration of a TDP-43-expressing neuron without inducing any significant injury to surrounding cells.

To examine the response of spinal microglia to the degeneration of a single spinal motor neuron, we generated transgenic fish that co-express cytoplasmic mTagBFP in motor neurons [17] and mCherry-CAAX in macrophages/
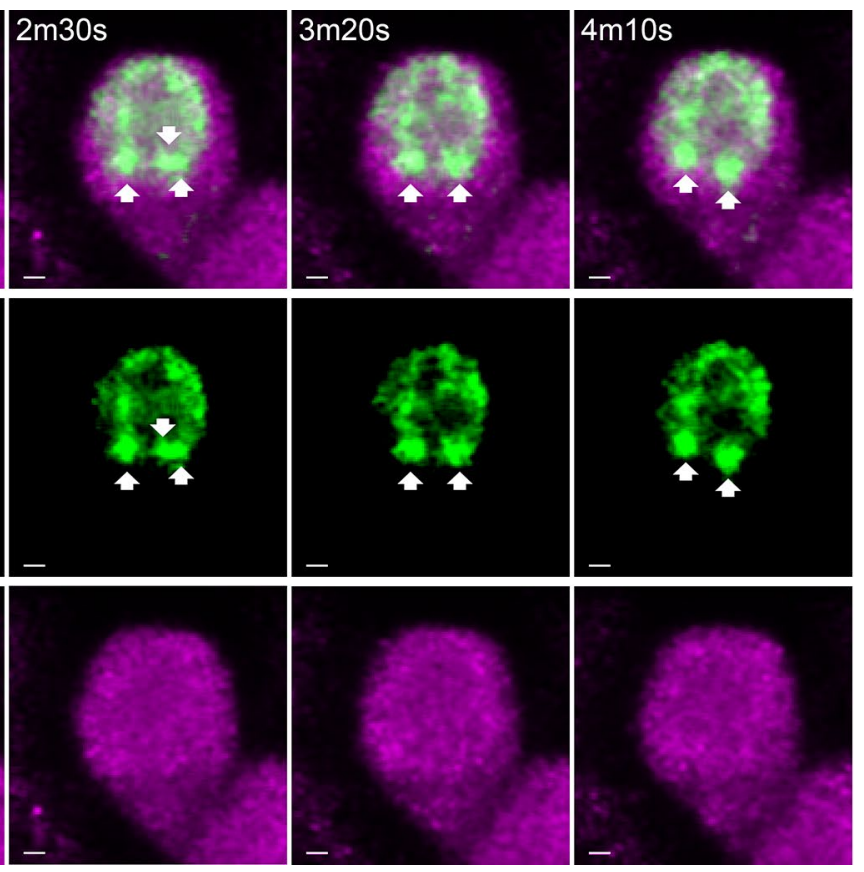

lapse video gives the best example of the TDP-43 motility (Online Resource 1). Arrows indicate and follow distinct accumulations over the imaging period. Scale $=1 \mu \mathrm{m}$

microglia (mpeg1.1 promoter, [18]), respectively. Using DNA injections of eGFP-TDP43 ${ }^{\text {WT }}$ into these larvae we achieved expression of tagged TDP-43 in individual spinal motor neurons that allowed precise visualisation of TDP43 distribution after laser ablation ( $n=7$ motor neurons in 6 larvae).

Following targeted injury, individual spinal microglia could be observed to approach the injured neuron either to phagocytose the cell soma $(n=3$; Fig. 3 and Online Resource 2) or to establish contact without phagocytosis $(n=3$; Online Resource 3; one other neuron showed no morphology change or microglia response within a $6 \mathrm{~h}$ imaging period). The microglia response was swift and occurred within 1-2 h post-injury. The response was directed as the microglia cell body moved towards the injury site and extended cell processes towards the target membrane. We have previously characterised and quantified this phagocytic behaviour in more detail [40]. Overall we confirmed that UV-induced neuron degeneration triggers a local microglia response while sub-lethal stress results in a transient microglia interaction (Online Resource 3).

In three experiments in which we observed microglia phagocytosis of targeted neurons, the microglia ingested TDP-43 as part of their phagocytic response. Visualising the localisation of eGFP-TDP $43^{\mathrm{WT}}$ during this process showed that during laser-induced neuronal degeneration 


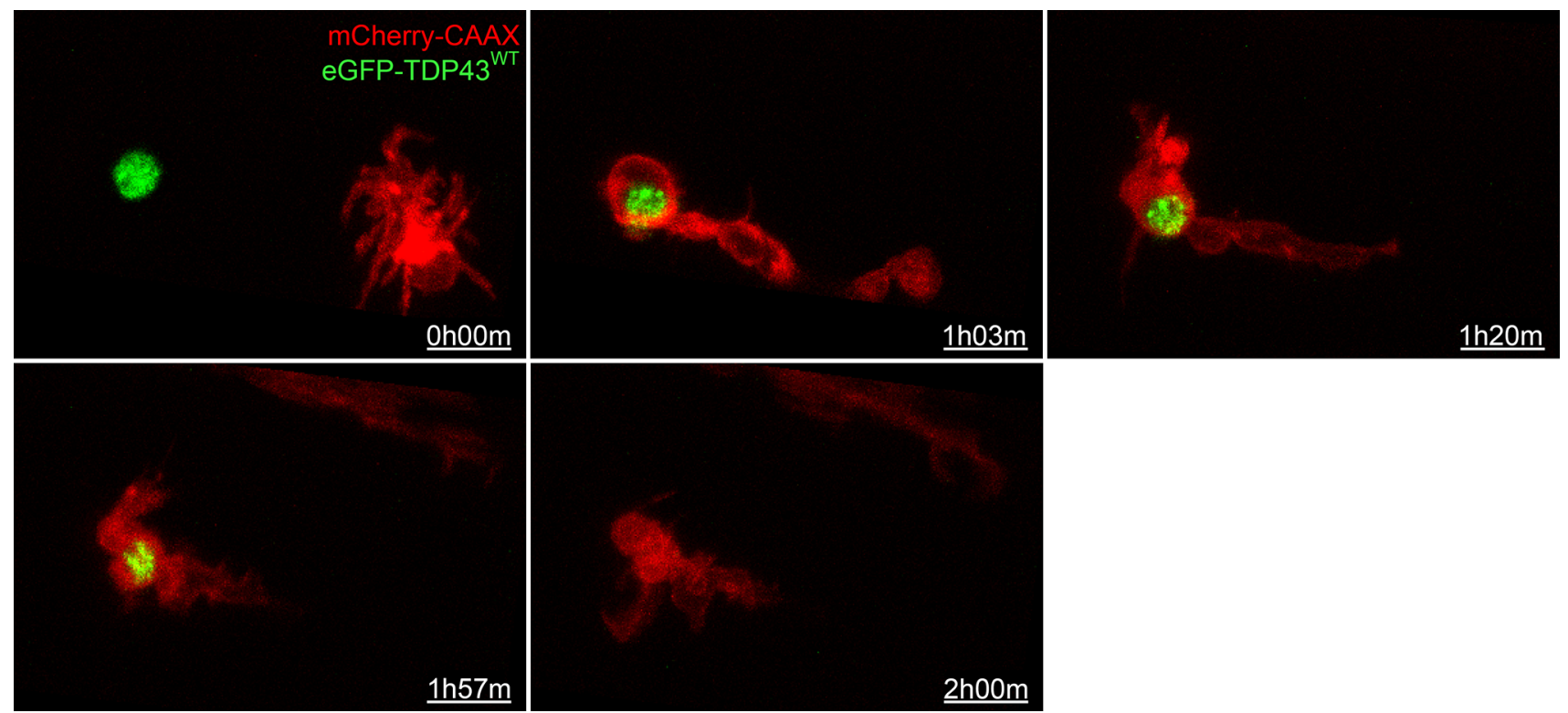

Fig. 3 Microglial uptake of TDP-43. Sequence of a spinal microglia (mCherry-CAAX, red) migrating toward and engulfing an eGFP-TDP43 ${ }^{\text {WT }}$ (green)-expressing motor neuron during UV-induced degeneration. Scale $=10 \mu \mathrm{m}$

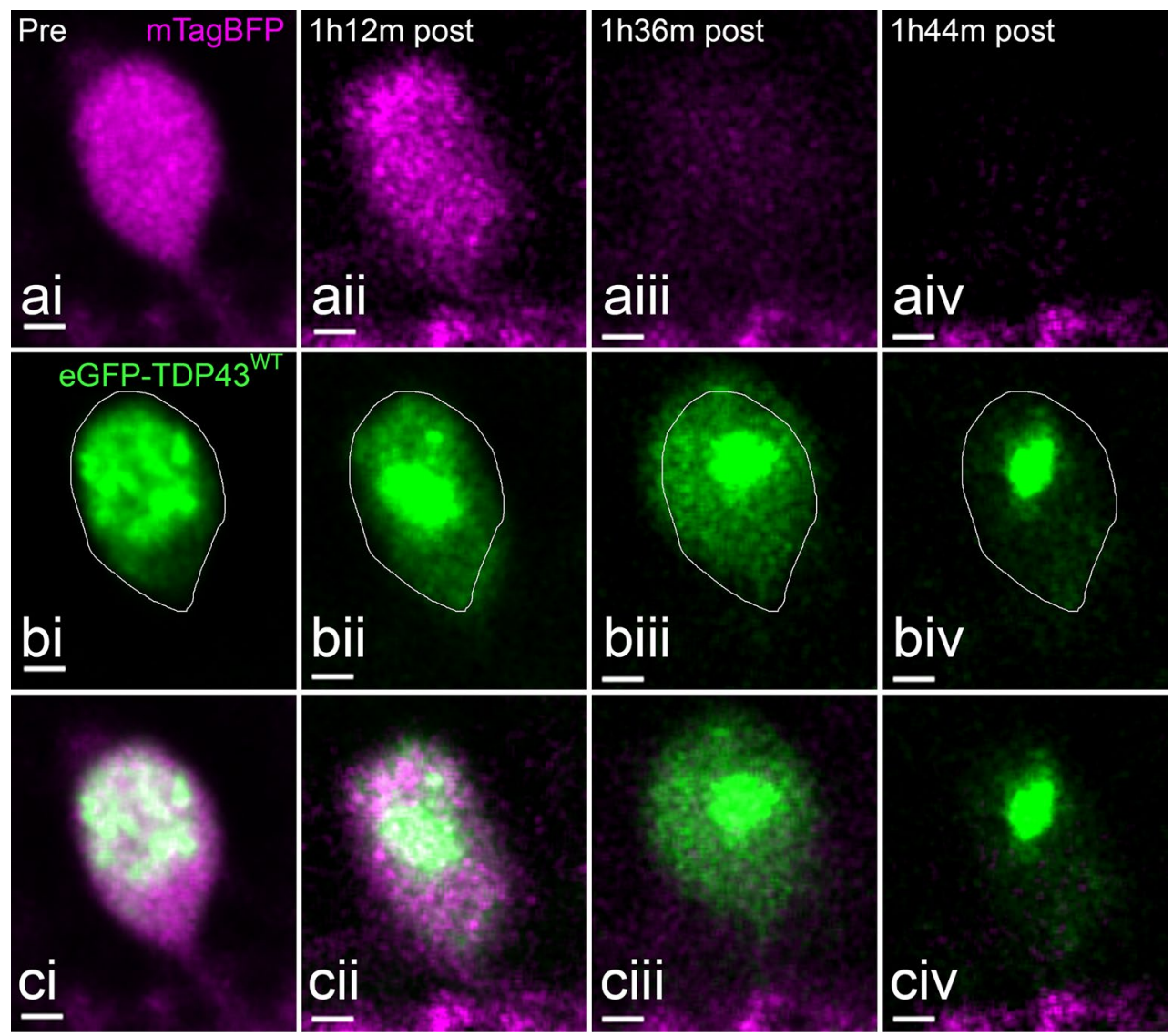

Fig. 4 Expansion and dissolution of a motor neuron over the course of UV-induced degeneration in the absence of microglia. ai Cytoplasmic mTagBFP signal pre-irradiation. aii-iv Cytoplasmic changes during UV-induced degeneration. bi eGFP-TDP43 ${ }^{\mathrm{WT}}$ distribution in the soma of the neuron pre-irradiation. bii-iv eGFP-TDP43 ${ }^{\mathrm{WT}}$ mislocalises into the cytoplasm during degeneration. c Merged images. Scale $=2 \mu \mathrm{m}$ 


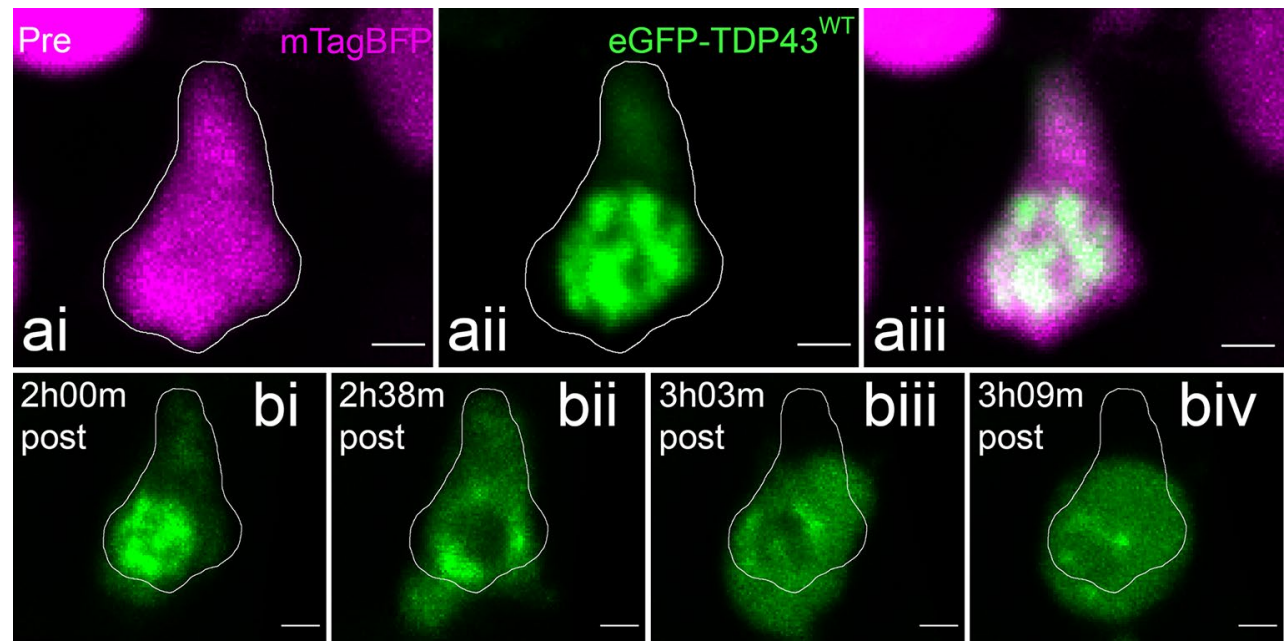

Fig. 5 Blebbing and TDP-43 mislocalisation in a motor neuron over the course of UV-induced degeneration after depletion of microglia. ai Cytoplasmic mTagBFP signal pre-irradiation. aii eGFP-TDP43 ${ }^{\text {WT }}$ distribution in the soma of the neuron pre-irradiation. aiii Merged images. bi-iv eGFP-TDP43 ${ }^{\mathrm{WT}}$ signal redistributes into the cyto- plasm and shows the blebbing of the cell soma during degeneration. Note the apparent fragmentation of the nucleus, in contrast to the concentration of nuclear eGFP-TDP43 ${ }^{\mathrm{WT}}$ in the previous figure. Scale $=2 \mu \mathrm{m}$
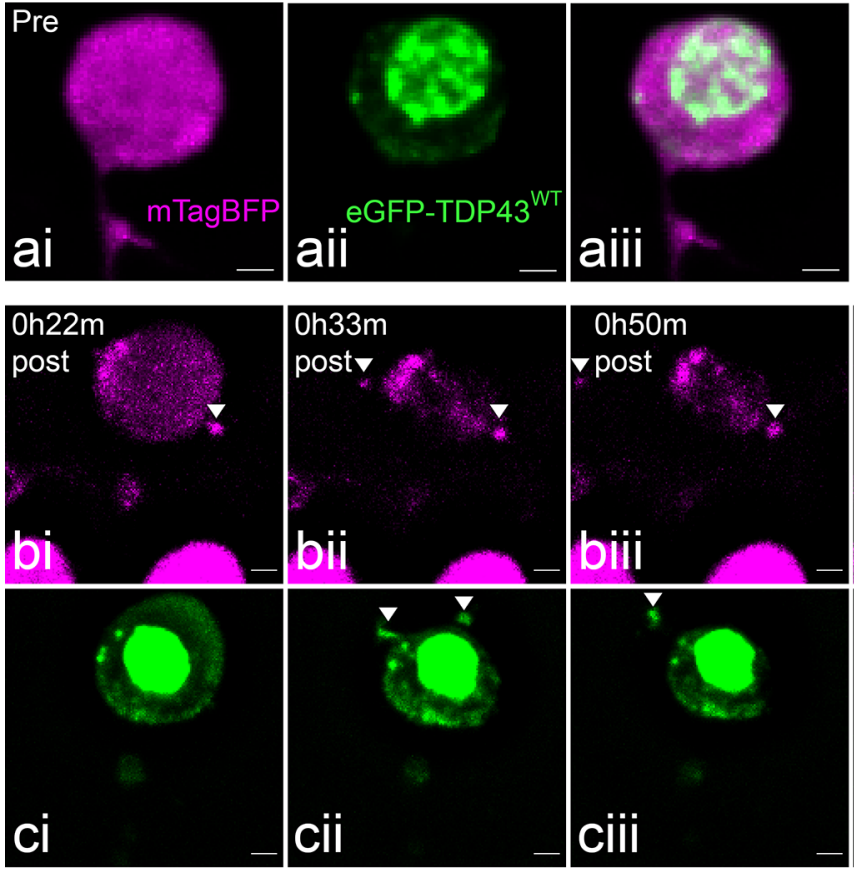

Fig. 6 Fragment release from a neuron undergoing UV-induced degeneration in the absence of functional microglia. ai Cytoplasmic mTagBFP signal pre-irradiation. aii eGFP-TDP43 ${ }^{\text {WT }}$ distribution in the soma pre-irradiation. aiii Merged images. bi-vi mTagBFP during UV-induced degeneration. Concentrated fragments can be observed

microglia internalised TDP-43 predominantly as a component of the neuron nucleus. The fluorescence was lost rapidly (between frames, $<4 \mathrm{~min}$ ) in the microglial phagosome, likely due to lysosomal fusion and rapid separating from the external membrane before the cytoplasm disperses. ci-vi eGFP-TDP43 $3^{\mathrm{WT}}$ during degeneration. Concentrated fragments can be observed collecting and releasing from the membrane. The concentrated (pyknotic) nuclear core gradually fragments. Scale $=2 \mu \mathrm{m}$

acidification of the organelle [48]. This is reminiscent of the finding in the zebrafish tectum that microglia phagocytosis occurs early in the cell death process, usually preceding the binding of extracellular AnnexinV $[48,62]$ and 

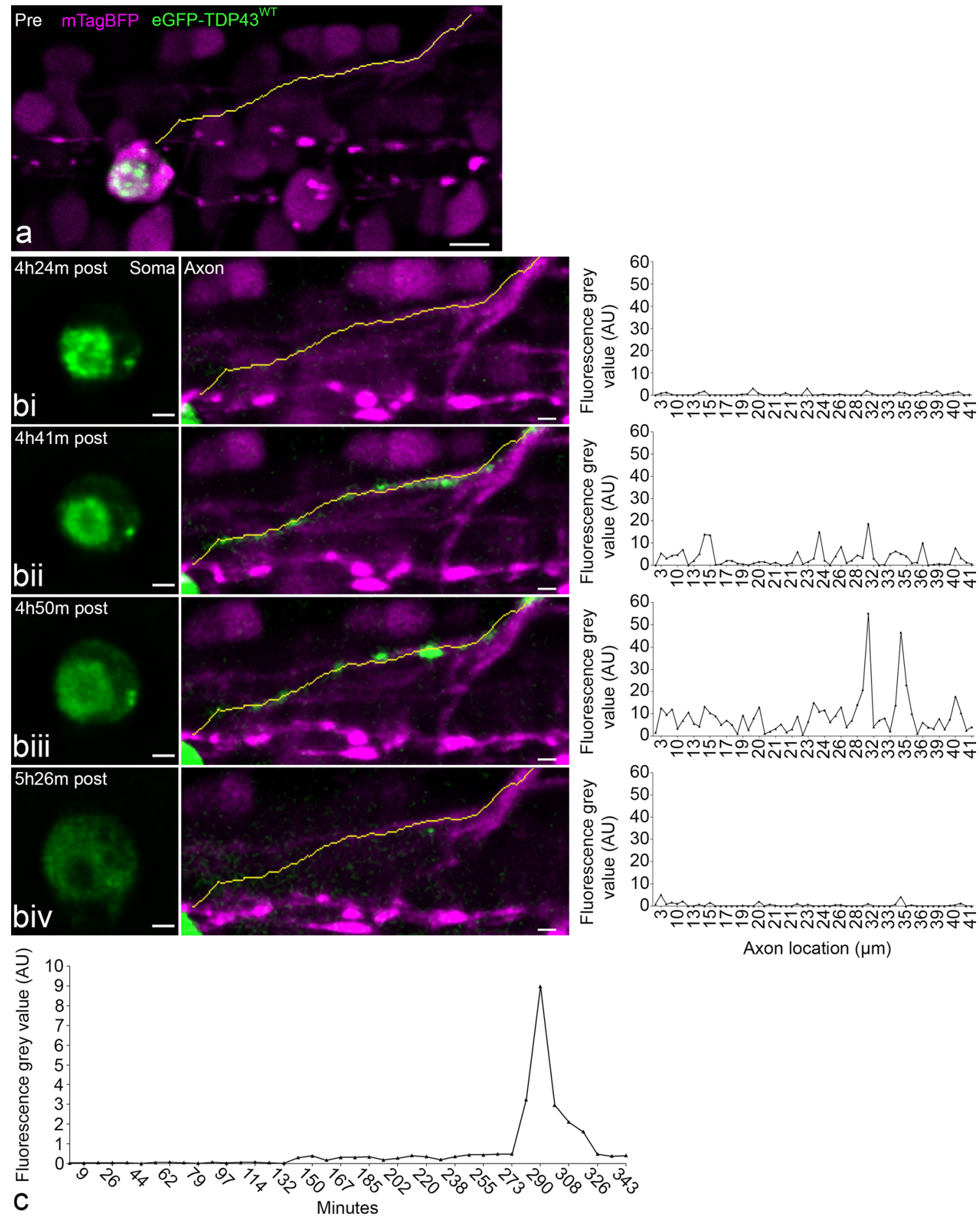

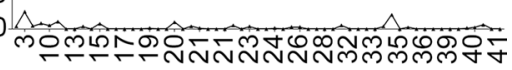
Axon location $(\mu \mathrm{m})$

Fig. 7 Axonal redistribution of eGFP-TDP43 ${ }^{\text {WT }}$ during UV-induced degeneration and microglia depletion. a Pre-irradiation, line is a projection of the axon vector used for signal analysis. Scale $=5 \mu \mathrm{m}$. biiv At each time point from left to right the three windows represents a single time point illustrating the cell body and the TDP-43 distribution (soma, eGFP-TDP43 ${ }^{\mathrm{WT}}$ in green), the axonal projection (axon,
mTagBFP in magenta incl. neurite vector as yellow line), and the fluorescence intensity of eGFP in the segments along the neurite vector. c Line graph demonstrating the time course of the mean eGFP fluorescence intensity along the axon post-stress induction. Scale $=2 \mu \mathrm{m}$. Note: axonal redistribution was observed in 2 of the 10 neurons, which were targeted for UV injury and underwent degeneration 
suggests that microglia play an important role in phagocytosing degenerating motor neurons and intraneuronal TDP-43.

\section{Depletion of microglia revealed the sequence of neurodegeneration and TDP-43 redistribution}

To fully elucidate the fate of TDP-43 in a dying motor neuron in vivo, we inhibited microglial phagocytosis by morpholino targeting of PU.1 (zebrafish spilb, see "Materials and methods"). PU.1 is a well-characterised transcription factor and essential for monocyte to macrophage lineage progression, and knockdown of PU.1 has been shown to reliably cause macrophage deficiency in zebrafish [25, 48-50].

Larvae were injected with a PU.1-targeted morpholino or a 4-bp-mismatch control and screened for effective macrophage knockdown as well as common morpholino-associated developmental abnormalities [5]. Specific morpholinoinduced abnormalities were not observed [Supplementary Fig. 3a (Online Resource 10)] and macrophage knockdown was confirmed at $72 \mathrm{~h}$ post-fertilisation (hpf) [Supplementary Fig. 3b (Online Resource 10)]. Repopulation of macrophages in these knockdown larvae had begun at $120 \mathrm{hpf}$.

Within the 72-120-hpf time window, spinal cord motor neurons were injured with the laser as described $(n=14$ cells in 12 larvae). In the absence of the primary macrophages, targeted motor neurons underwent a consistent process of degeneration. Following injury, the motor neuron cell bodies showed swelling ( $n=10$ of 14 , Figs. 4, 5). At its maximum, the cell became spherical in shape (Figs. 4ciii, 5 biv, 6ci, 7biv). The time taken to reach this full expansion was variable ( $22 \mathrm{~min}$ to $5 \mathrm{~h} 26 \mathrm{~min}$ ). However, within minutes of reaching this morphology, all neurons rapidly shrunk and lost the majority of the cytoplasmic fluorescent signal as it became dispersed to the extracellular space (Online Resources 4 and 5).

Importantly, during the phase of cellular expansion, eGFP-TDP $43^{\mathrm{WT}}$ rapidly redistributed from the nucleus to the cytoplasm (Figs. 4b, 5b). This process was confirmed using high-frequency image acquisition $(8 \mathrm{kHz}$ resonance scanner sequence, Online Resource 6). The nucleus remained visible as the brightest accumulation of eGFP-TDP $43^{\mathrm{WT}}$ in either a condensed form (pyknotic) (Fig. 4biii) or it became fragmented (karyorrhexic) (Fig. 5 bii-iv). In the case of pyknosis, the remaining core of nuclear eGFP-TDP43 ${ }^{\mathrm{WT}}$ persisted initially and disintegrated slowly thereafter (see next section).

\section{TDP-43 fragments are released by dying motor neurons}

Prior to the expansion and dissolution of the degenerating neuron, and in the absence of phagocytosing microglia, we occasionally observed fluorescently tagged fragments moving from the cytoplasm into the extracellular space. As shown in Fig. 6 and Online Resource 7, these fragments occasionally contained eGFP-TDP43 ${ }^{\mathrm{WT}}$. After expansion and dissolution, and after the nucleus had assumed a pyknotic morphology, the remaining core of eGFP-TDP43 ${ }^{\text {WT }}$ could be observed to gradually fragment and disperse (Fig. 6cvi and best illustrated live in Online Resource 7).

\section{Axonal mislocalisation of TDP-43 prior to cellular disintegration}

In addition to morphological alterations of the cell body, we also observed beading and disintegration of the axon as a sequela of UV-induced degeneration of spinal motor neurons (Online Resource 8). To follow up on this, we investigated whether the mislocalisation of TDP-43 into the cytoplasm was accompanied by an increase in axonal TDP-43. To establish a baseline, we examined eGFP-TDP43 ${ }^{\mathrm{WT}}$ distribution in the axons of uninjured neurons in $\mathrm{mKO} 2$-CAAX co-expressing larvae. eGFP-TDP43 ${ }^{\mathrm{WT}}$ was not detected along the axon proximal to the cell body $[n=8$ neurons in three larvae, Supplementary Fig. 4 (Online Resource 10)]. Similarly, for the motor neurons targeted by UV to induce degeneration, such as the neuron demonstrated in Fig. 7, no eGFP-TDP $43^{\mathrm{WT}}$ was detectable along the motor axon from the hillock to its conjunction with the axon bundle leading down into the myotome, whereas mTagBFP was present throughout the cytoplasm and along the axon. However, in two of the ten motor neurons that underwent UV-induced degeneration, we observed that the process of cellular expansion was accompanied by a rapid movement of eGFPTDP $43^{\mathrm{WT}}$ into the axon. The process is illustrated in Fig. 7 and Online Resource 9, both visually and by plotting the eGFP fluorescence intensity along the 3D traced axon over time. Following injury, the mean eGFP-TDP43 ${ }^{\mathrm{WT}}$ intensity along the axon increased during the process of degeneration before spiking rapidly $\sim 5 \mathrm{~h}$ after the initial UV stress (but prior to dissolution as described above). The observation of inducible spreading of TDP-43 into axons in a living organism points to the existence of a potential molecular mechanism for progressive transmission and redistribution of pathological TDP-43 to neighbouring and distal neurons within the motor system.

\section{Discussion}

Our understanding of the molecular pathogenesis of ALS and FTLD is limited by our incomplete understanding of the sequence of events underpinning the pathology. Many of the insights we currently have on the hallmarks of ALS/ FTLD were derived from postmortem histological studies. 
a

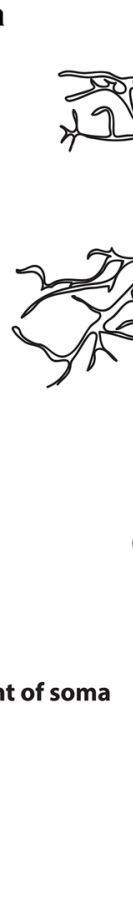

TDP-43 distribution:

Cell soma vs. Nucleus

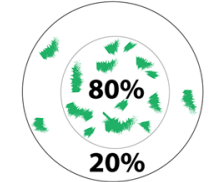

UV-induced cell death
+ Microglia

b

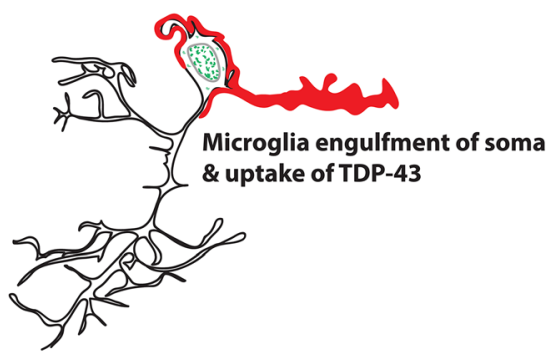

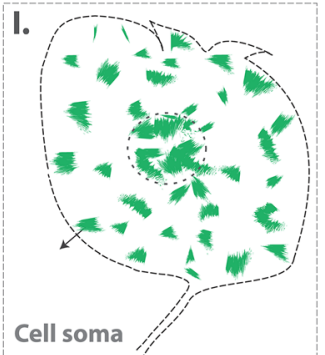

1: Swelling

2: Mislocalisation of TDP-43

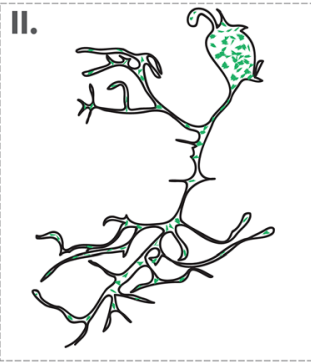

3: Axonal redistribution

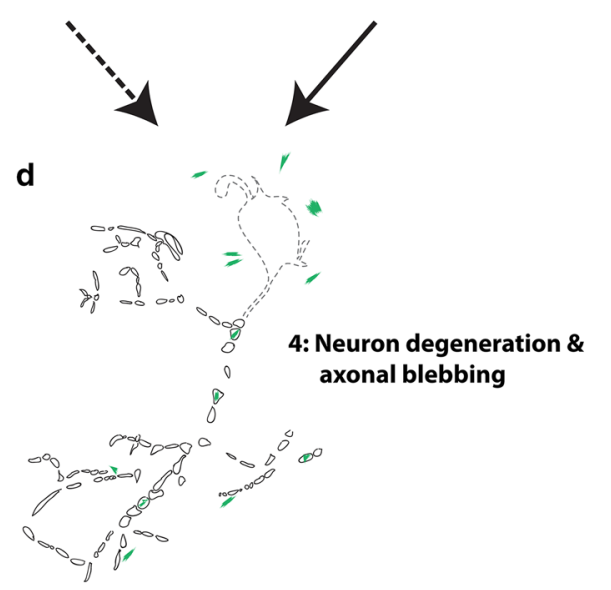

Fig. 8 Illustration of the proposed in vivo process of stress-induced degeneration of a neuron in the zebrafish spinal cord. a An uninjured spinal motor neuron expressing fluorescent TDP-43 (green) predominantly in the nucleus. Insert depicts the measured distribution of TDP-43 between the cytoplasmic and nuclear compartments in the cell soma volume with $\sim 80 \%$ TDP-43 localised in the nucleus (dotted line) and $\sim 20 \%$ localised in the cytoplasm. b In the presence of microglia (red), the stressed/injured neuron is rapidly recognised and phagocytosed by the microglial cell. TDP-43 is taken up and contained during this process. $\mathbf{c}$ In the absence of microglia, the stressed/ injured neuron undergoes a characteristic sequence of neurodegeneration and TDP-43 redistribution (I-II). Individual stages of this process have been described previously in clinical literature and are cited

In almost all ALS patients and more than half of FTLD patients, the key molecular histopathological hallmark is the presence of abnormal amounts of intracellularly deposited TDP-43. It typically forms cytoplasmic-insoluble aggregates below (note that the continuous sequence of events has so far not been demonstrated in vivo). The cell soma shows dysmorphia with a distinctive swelling (dotted line, resembling expansion or "ballooning" observed across neurodegenerative histology: AD and CJD [16], SMA [37], HD [52], TDP-43 mislocalisation into the cytoplasm [23] and nuclear condensation [24]). At the end stage of this process TDP43 is redistributed along the axonal projections into the distal parts of the neuron [9-11]. d The degenerated neuron loses its integrity initially in the cell soma and shows characteristic blebbing of the degenerating axonal projections. Conceivably, the lack of neuroprotective microglia allows the spread of TDP-43 aggregates into the neuropil and extracellular tissue

within neurons $[3,43]$. Numerous in vitro models of TDP43 overexpression (wildtype and mutant) have been investigated to understand how these TDP-43 aggregates are formed. These studies collectively suggest that TDP-43 is a 
highly aggregation-prone protein [27] and that a variety of molecular pathways can lead to cytoplasmic mislocalisation, aggregation and inclusion formation [14, 20, 30, 56, 71]. Moreover, although a true phenocopy of ALS/FTLD has been elusive in TDP-43 animal models [26], the overexpression of mutant forms of TDP-43 in mice does result in the development of motor impairment and lethality [29, 58, 63]. A key challenge with these animal models is that similar to the clinical postmortem situation, the disease histopathology only provides snapshots at different time points during disease progression. In contrast, in the present study, we were able to observe the fate and dynamics of TDP-43 cytoplasmic deposition in real-time at high resolution within the spinal cord in vivo. Notably, we were able to identify distinct stages of motor neuron degeneration and the mislocalisation and spread of TDP-43. In Fig. 8, we summarise the temporal sequence of neurodegeneration and TDP-43 mislocalisation. While this process of UV-mediated injury can reflect an accelerated cell-death pathway, we occasionally observed the formation of TDP-43 aggregates in the cytoplasm of spinal motor neurons. It will be important to explore if these aggregates are of similar structure and function to the pathological aggregates (e.g. phosphorylation status of TDP-43) that are observed in diseased human postmortem tissue and in animal models overexpressing mutant TDP-43.

The subcellular redistribution of TDP-43 from the nucleus to the cytoplasm in injured motor neurons (when microglia were depleted and, therefore, the cells were not rapidly phagocytosed) was especially striking, and this study represents the first real-time in vivo observation of the phenomenon. This redistribution of TDP-43 to the cytoplasm has been suggested to represent a landmark feature of the onset and progression of ALS/FTLD [23, 43], and in cell culture the disrupted trafficking of TDP-43 is a precursor to the formation of cytoplasmic TDP-43 inclusions [66]. Previously, Sato et al., [54] have reported the cytoplasmic mislocalisation of TDP-43 in response to neuronal stress in a mouse ligation model. Our observations provide in vivo support for the hypothesis that cytoplasmic accumulation of TDP-43 in motor neurons could occur as a direct downstream consequence of neuronal stress or injury. It is important to point out that in our experiments microglia did not directly prevent the cytoplasmic mislocalisation of TDP-43 in UV-injured motor neurons, rather this process was circumvented by the microglial phagocytosis of the degenerating neuron. This raises an intriguing question-why is TDP-43 pathology limited to ALS/FTLD and not other neurodegenerative diseases (such as Alzheimer's, Parkinson's and Huntington diseases)? It is possible that the TDP-43 redistribution that we have observed is elicited by specific types of neuronal stress/injury (such as UV that was used in this study). Alternatively, it is possible that microglia are specifically defective in their phagocytic function in ALS/
FTLD (and not other diseases), therefore, allowing intracellular TDP-43 redistribution to occur. These are important directions for future follow-up. Interestingly, Spiller and colleagues recently demonstrated the selective uptake of TDP-43 by reactive microglia in mice, and that this process is likely to play an important role in clearing pathological (mislocalised) TDP-43 from neurons [59].

Significant recent interest in the field has focussed on the potential cell-to-cell transfer of TDP-43 and/or associated proteins, and the possibility that this might facilitate propagation of the disease process through the motor system. In vitro, the intercellular transfer of TDP-43 has been demonstrated [21, 47, 57, 67]. However, whether this also occurs in vivo remains an open question. In our study, we observed two pathways for transfer of TDP-43 from the originating dying neuron: uptake by microglia via direct phagocytosis and transfer into the surrounding neuropil.

UV injury-induced degeneration resulted in a phagocytic response by spinal microglia, which took up predominantly nuclear TDP-43. This represents the first in vivo demonstration of TDP-43 uptake by microglia as well as the prevention of TDP-43 spreading by normal microglia. Further study into the fate of TDP-43 and whether microglial function is altered following TDP-43 uptake in the zebrafish model may help expand upon the early evidence for microglial involvement in the progression of ALS/FTLD [8, 35, 46]. For example, phagocytosis of degradation-resistant TDP43 aggregates [69] may disrupt the lysosomal pathway in microglia and, therefore, impair their ability for clearance of TDP-43. Interestingly, Paolicelli et al. have recently reported that TDP-43 depletion in $\mathrm{Cx} 3 \mathrm{Cr} 1$-expressing cells (including microglia) led to an increase of phagocytosis and elevated transcription of lysosomal components [46]. This suggests that both endogenous and exogenously acquired TDP-43 may alter the functional behaviour of microglia, and contribute towards the progression of ALS/FTLD.

Depletion of microglia through PU.1 knockdown allowed us to visualise intracellular spreading of TDP43. In fact, we observed at least three pathways for TDP43 dispersal following motor neuron degeneration after injury: this included diffusion of TDP-43 from the nucleus to the cytoplasm after neuronal swelling, compartmentalised TDP-43 release in discrete quanta, and the breakdown of homeostatic TDP-43 exclusion from the axon. Concerning the interesting axonal spreading of TDP-43 it is important to note that we consistently did not detect any eGFP-TDP $43^{\mathrm{WT}}$ inside axons of healthy spinal motor neurons. Neuronal cell cultures and drosophila imaging have identified axonal TDP-43 as a component of transport vesicles in keeping with a role as a chaperone of RNA transport [2, 19]. We frequently observed the cytoplasmic mTagBFP and the CAAX-tagged membrane-bound $\mathrm{mKO} 2$ fluorophores incorporated into transport vesicles moving 
antero- as well as retro-grade along the axon (data not shown). However, we never observed this active transport for eGFP-TDP43 ${ }^{\mathrm{WT}}$. This difference indicates the intriguing possibility that the incorporation of TDP-43 into transport vesicles may be differentially regulated between neuronal cell types, in an in vivo setting (i.e. cell culture vs vertebrate spinal cord) or in distinct environmental or developmental contexts.

This study provides the first live-imaging data to support axonal-mediated spreading of TDP-43 [9, 45]. In combination with observations obtained in cell cultures suggesting TDP-43 transfer via the axonal membrane [21], this provides evidence that axonal TDP-43 might be an important mediator of ALS/FTLD pathology. It is worth noting that alongside our observations of spinal microglia engulfment of motor neuron cell bodies in this study and in two previous studies [40,41], we have never observed microglial phagocytosis of degenerating axons. Given that microglial neuronophagia preceded TDP-43 nucleocytoplasmic transport and that the anterograde movement of TDP-43 was a late process in neuron degeneration (that we could observe best when microglia were depleted), it is reasonable to conclude that rapid microglial phagocytosis of injured motor neuron somata is an effective mechanism for the prevention of TDP-43 spread.

Taken together, nucleo-cytoplasmic transport of TDP43 was studied in real time in the living spinal cord, and revealed that depletion of functional microglia leads to axonal and extracellular spreading of the pathological protein. This provides new insight into the potential direct role of microglia as well as pathways for protein distribution in the cascade of cellular and molecular events that cause ALS and FTLD.

Acknowledgements The authors would like to thank Thomas Hall in the Parton Lab at the University of Queensland for providing the kalTA4 and 4xnrUAS sequences. We also thank Leica Microsystems and in particular Stephen Thompson for their support. We wish to thank the Snow Foundation for their generous support towards establishing the transgenic zebrafish facility at Macquarie University.

\section{Compliance with ethical standards}

Funding This work was supported by MNDRIA (GIA 1838, GIA 1638-Cure for MND Research Grant), ARC (DP150104472) and donations made towards MND research at Macquarie University.

Conflict of interest The authors declare that they have no conflicts of interest.

Ethical approval All applicable international, national, and/or institutional guidelines for the care and use of animals were followed. All procedures performed in studies involving animals were in accordance with the ethical standards of the institution or practice at which the studies were conducted. This article does not contain any studies with human participants performed by any of the authors.
Open Access This article is distributed under the terms of the Creative Commons Attribution 4.0 International License (http://creativeco mmons.org/licenses/by/4.0/), which permits unrestricted use, distribution, and reproduction in any medium, provided you give appropriate credit to the original author(s) and the source, provide a link to the Creative Commons license, and indicate if changes were made.

\section{References}

1. Afroz T, Hock EM, Ernst P, Foglieni C, Jambeau M, Gilhespy LAB, Laferriere F, Maniecka Z, Plückthun A, Mittl P, Paganetti P, Allain FHT, Polymenidou M (2017) Functional and dynamic polymerization of the ALS-linked protein TDP-43 antagonizes its pathologic aggregation. Nat Commun 8:45. https://doi. org/10.1038/s41467-017-00062-0

2. Alami NH, Smith RB, Carrasco MA, Williams LA, Winborn CS, Han SSW, Kiskinis E, Winborn B, Freibaum BD, Kanagaraj A, Clare AJ, Badders NM, Bilican B, Chaum E, Chandran S, Shaw CE, Eggan KC, Maniatis T, Taylor JP (2014) Axonal transport of TDP-43 mRNA granules is impaired by ALS-causing mutations. Neuron 81:536-543. https://doi.org/10.1016/j.neuron.2013.12.018

3. Arai T, Hasegawa M, Akiyama H, Ikeda K, Nonaka T, Mori H, Mann D, Tsuchiya K, Yoshida M, Hashizume Y, Oda T (2006) TDP-43 is a component of ubiquitin-positive tau-negative inclusions in frontotemporal lobar degeneration and amyotrophic lateral sclerosis. Biochem Biophys Res Commun 351:602-611. https ://doi.org/10.1016/j.bbrc.2006.10.093

4. Ayala YM, Zago P, D'Ambrogio A, Xu Y-F, Petrucelli L, Buratti E, Baralle FE (2008) Structural determinants of the cellular localization and shuttling of TDP-43. J Cell Sci 121:3778-3785. https ://doi.org/10.1242/jcs.038950

5. Bedell VM, Westcot SE, Ekker SC (2011) Lessons from morpholino-based screening in zebrafish. Brief Funct Genomics 10:181-188. https://doi.org/10.1093/bfgp/elr021

6. Boeynaems S, Bogaert E, Van Damme P, Van Den Bosch L (2016) Inside out: the role of nucleocytoplasmic transport in ALS and FTLD. Acta Neuropathol 132:159-173. https://doi.org/10.1007/ s00401-016-1586-5

7. Boeynaems S, Bogaert E, Kovacs D, Konijnenberg A, Timmerman E, Volkov A, Guharoy M, De Decker M, Jaspers T, Ryan VH, Janke AM, Baatsen P, Vercruysse T, Kolaitis R-M, Daelemans D, Taylor JP, Kedersha N, Anderson P, Impens F, Sobott F, Schymkowitz J, Rousseau F, Fawzi NL, Robberecht W, Van Damme P, Tompa P, Van Den Bosch L (2017) Phase separation of C9orf72 dipeptide repeats perturbs stress granule dynamics. Mol Cell 65:1044-1055. https://doi.org/10.1016/j.molcel.2017.02.013

8. Boillée S, Yamanaka K, Lobsiger CS, Copeland NG, Jenkins NA, Kassiotis G, Kollias G, Cleveland DW (2006) Onset and progression in inherited ALS determined by motor neurons and microglia. Science 312:1389-1392. https://doi.org/10.1126/science.1123511

9. Braak H, Brettschneider J, Ludolph AC, Lee VM, Trojanowski JQ, Del Tredici K (2013) Amyotrophic lateral sclerosis-a model of corticofugal axonal spread. Nat Rev Neurol 9:708-714. https:// doi.org/10.1038/nrneurol.2013.221

10. Braak H, Ludolph A, Thal DR, Del Tredici K (2010) Amyotrophic lateral sclerosis: dash-like accumulation of phosphorylated TDP43 in somatodendritic and axonal compartments of somatomotor neurons of the lower brainstem and spinal cord. Acta Neuropathol 120:67-74. https://doi.org/10.1007/s00401-010-0683-0

11. Brettschneider J, Del Tredici K, Toledo JB, Robinson JL, Irwin DJ, Grossman M, Suh E, Van Deerlin VM, Wood EM, Baek Y, Kwong L, Lee EB, Elman L, McCluskey L, Fang L, Feldengut S, 
Ludolph AC, Lee VM-Y, Braak H, Trojanowski JQ (2013) Stages of pTDP-43 pathology in amyotrophic lateral sclerosis. Ann Neurol 74:20-38. https://doi.org/10.1002/ana.23937

12. Budini M, Buratti E, Stuani C, Guarnaccia C, Romano V, De Conti L, Baralle FE (2012) Cellular model of TAR DNA-binding protein 43 (TDP-43) aggregation based on its C-terminal Gln/Asn-rich region. J Biol Chem 287:7512-7525. https://doi.org/10.1074/jbc. M111.288720

13. Burrell JR, Halliday GM, Kril JJ, Ittner LM, Götz J, Kiernan MC, Hodges JR (2016) The frontotemporal dementia-motor neuron disease continuum. Lancet 388:919-931. https://doi.org/10.1016/ S0140-6736(16)00737-6

14. Conicella AE, Zerze GH, Mittal J, Fawzi NL (2016) ALS mutations disrupt phase separation mediated by $\alpha$-helical structure in the TDP-43 low-complexity C-terminal domain. Structure 24:1537-1549. https://doi.org/10.1016/j.str.2016.07.007

15. Davidson Y, Kelley T, Mackenzie IRA, Pickering-Brown S, Du Plessis D, Neary D, Snowden JS, Mann DMA (2007) Ubiquitinated pathological lesions in frontotemporal lobar degeneration contain the TAR DNA-binding protein, TDP-43. Acta Neuropathol 113:521-533. https://doi.org/10.1007/s00401-006-0189-y

16. Dickson DW, Yen S-H, Suzuki KI, Davies P, Garcia JH, Hirano A (1986) Ballooned neurons in select neurodegenerative diseases contain phosphorylated neurofilament epitopes. Acta Neuropathol 71:216-223

17. Don EK, Formella I, Badrock AP, Hall TE, Morsch M, Hortle E, Hogan A, Chow S, Gwee SSL, Stoddart JJ, Nicholson G, Chung R, Cole NJ (2017) A Tol2 gateway-compatible toolbox for the study of the nervous system and neurodegenerative disease. Zebrafish 14:69-72. https://doi.org/10.1089/zeb.2016.1321

18. Ellett F, Pase L, Hayman JW, Andrianopoulos A, Lieschke GJ (2011) mpeg1 promoter transgenes direct macrophage-lineage expression in zebrafish. Blood 117:e49-e56. https://doi. org/10.1182/blood-2010-10-314120

19. Fallini C, Bassell GJ, Rossoll W (2012) The ALS disease protein TDP-43 is actively transported in motor neuron axons and regulates axon outgrowth. Hum Mol Genet 21:3703-3718. https://doi. org/10.1093/hmg/dds205

20. Farrawell NE, Lambert-Smith IA, Warraich ST, Blair IP, Saunders DN, Hatters DM, Yerbury JJ (2015) Distinct partitioning of ALS associated TDP-43, FUS and SOD1 mutants into cellular inclusions. Sci Rep 5:13416. https://doi.org/10.1038/srep13416

21. Feiler MS, Strobel B, Freischmidt A, Helferich AM, Kappel J, Brewer BM, Li D, Thal DR, Walther P, Ludolph AC, Danzer KM, Weishaupt JH (2015) TDP-43 is intercellularly transmitted across axon terminals. J Cell Biol 211:897-911. https://doi.org/10.1083/ jcb. 201504057

22. Geser F, Lee VM-Y, Trojanowski JQ (2010) Amyotrophic lateral sclerosis and frontotemporal lobar degeneration: a spectrum of TDP-43 proteinopathies. Neuropathology 30:103-112. https://doi. org/10.1111/j.1440-1789.2009.01091.x

23. Giordana MT, Piccinini M, Grifoni S, De Marco G, Vercellino M, Magistrello M, Pellerino A, Buccinnà $\mathrm{B}$, Lupino E, Rinaudo MT (2010) TDP-43 redistribution is an early event in sporadic amyotrophic lateral sclerosis. Brain Pathol 20:351-360. https:// doi.org/10.1111/j.1750-3639.2009.00284.x

24. Graeber MB, Moran LB (2002) Mechanisms of cell death in neurodegenerative diseases: fashion, fiction, and facts. Brain Pathol 12:385-390. https://doi.org/10.1111/j.1750-3639.2002. tb00452.x

25. van Ham TJ, Kokel D, Peterson RT (2012) Apoptotic cells are cleared by directional migration and elmo1-dependent macrophage engulfment. Curr Biol 22:830-836. https://doi. org/10.1016/j.cub.2012.03.027

26. Ittner LM, Halliday GM, Kril JJ, Götz J, Hodges JR, Kiernan MC (2015) FTD and ALS—-translating mouse studies into clinical trials. Nat Rev Neurol 11:360-366. https://doi.org/10.1038/nrneu rol.2015.65

27. Johnson BS, Snead D, Lee JJ, McCaffery JM, Shorter J, Gitler AD (2009) TDP-43 is intrinsically aggregation-prone, and amyotrophic lateral sclerosis-linked mutations accelerate aggregation and increase toxicity. J Biol Chem 284:20329-20339. https://doi. org/10.1074/jbc.M109.010264

28. Kawakami K (2004) Transgenesis and gene trap methods in zebrafish by using the Tol2 transposable element. Methods Cell Biol 77:201-222. https://doi.org/10.1016/S0091-679X(04)77011 $-9$

29. Ke YD, van Hummel A, Stevens CH, Gladbach A, Ippati S, Bi M, Lee WS, Krüger S, van der Hoven J, Volkerling A, Bongers A, Halliday G, Haass NK, Kiernan M, Delerue F, Ittner LM (2015) Short-term suppression of A315T mutant human TDP-43 expression improves functional deficits in a novel inducible transgenic mouse model of FTLD-TDP and ALS. Acta Neuropathol 130:661-678. https://doi.org/10.1007/s00401-015-1486-0

30. Kim H-J, Raphael AR, LaDow ES, McGurk L, Weber RA, Trojanowski JQ, Lee VM-Y, Finkbeiner S, Gitler AD, Bonini NM (2013) Therapeutic modulation of eIF2 $\alpha$ phosphorylation rescues TDP-43 toxicity in amyotrophic lateral sclerosis disease models. Nat Genet 46:152-160. https://doi.org/10.1038/ng.2853

31. Kirshner H, Aguet F, Sage D, Unser M (2013) 3-D PSF fitting for fluorescence microscopy: implementation and localization application. J Microsc 249:13-25. https://doi.org/10.111 1/j.1365-2818.2012.03675.x

32. Kuo PH, Doudeva LG, Wang YT, Shen CKJ, Yuan HS (2009) Structural insights into TDP-43 in nucleic-acid binding and domain interactions. Nucleic Acids Res 37:1799-1808. https:// doi.org/10.1093/nar/gkp013

33. Kwan KM, Fujimoto E, Grabher C, Mangum BD, Hardy ME, Campbell DS, Parant JM, Yost HJ, Kanki JP, Chien CB (2007) The Tol2kit: a multisite gateway based construction kit for Tol2 transposon transgenesis constructs. Dev Dyn 236:3088-3099. https://doi.org/10.1002/dvdy.21343

34. Lagier-Tourenne C, Polymenidou M, Hutt KR, Vu AQ, Baughn M, Huelga SC, Clutario KM, Ling S-C, Liang TY, Mazur C, Wancewicz E, Kim AS, Watt A, Freier S, Hicks GG, Donohue JP, Shiue L, Bennett F, Ravits J, Cleveland DW, Yeo GW (2012) Divergent roles of ALS-linked proteins FUS/TLS and TDP-43 intersect in processing long pre-mRNAs. Nat Neurosci 15:1488-1497. https ://doi.org/10.1038/nn.3230

35. Leal-Lasarte MM, Franco JM, Labrador-Garrido A, Pozo D, Roodveldt C (2017) Extracellular TDP-43 aggregates target MAPK/MAK/MRK overlapping kinase (MOK) and trigger caspase-3/IL-18 signaling in microglia. FASEB J 31:2797-2816. https://doi.org/10.1096/fj.201601163R

36. Longair MH, Baker DA, Armstrong JD (2011) Simple neurite tracer: open source software for reconstruction, visualization and analysis of neuronal processes. Bioinformatics 27:2453-2454. https://doi.org/10.1093/bioinformatics/btr390

37. Love S (2015) Spinal muscular atrophy (SMA): neuronal swelling. In: Love S, Perry A, Ironside J, Budka H (eds) Greenfield's neuropathology, 9th edn. CRC Press, Boca Raton, FL, p 838

38. Lowe J, Mirra SS, Hyman BT, Dickson DW (2008) Accumulation of intracellular proteins as inclusion bodies: proteinopathies. In: Love S, Louis DN, Ellison DW (eds) Greenfield's neuropathology, 8th edn. CRC Press, Boca Raton, pp 1031-1032

39. Moisse K, Volkening K, Leystra-Lantz C, Welch I, Hill T, Strong MJ (2009) Divergent patterns of cytosolic TDP-43 and neuronal progranulin expression following axotomy: implications for TDP43 in the physiological response to neuronal injury. Brain Res 1249:202-211. https://doi.org/10.1016/j.brainres.2008.10.021

40. Morsch M, Radford R, Lee A, Don EK, Badrock AP, Hall TE, Cole NJ, Chung R (2015) In vivo characterization of microglial 
engulfment of dying neurons in the zebrafish spinal cord. Front Cell Neurosci 9:321. https://doi.org/10.3389/fncel.2015.00321

41. Morsch M, Radford RAW, Don EK, Lee A, Hortle E, Cole NJ, Chung RS (2017) Triggering cell stress and death using conventional UV laser confocal microscopy. J Vis Exp 120:e54983. https ://doi.org/10.3791/54983

42. Nakano T, Windrem M, Zappavigna V, Goldman SA (2005) Identification of a conserved 125 base-pair $\mathrm{Hb} 9$ enhancer that specifies gene expression to spinal motor neurons. Dev Biol 283:474-485. https://doi.org/10.1016/j.ydbio.2005.04.017

43. Neumann M, Sampathu DM, Kwong LK, Truax AC, Micsenyi MC, Chou TT, Bruce J, Schuck T, Grossman M, Clark CM, McCluskey LF, Miller BL, Masliah E, Mackenzie IR, Feldman H, Feiden W, Kretzschamer HA, Trojanowski JQ, Lee VM-Y (2006) Ubiquitinated TDP-43 in frontotemporal lobar degeneration and amyotrophic lateral sclerosis. Science 314:130-133. https://doi. org/10.1126/science. 1134108

44. Nonaka T, Masuda-Suzukake M, Arai T, Hasegawa Y, Akatsu H, Obi T, Yoshida M, Murayama S, Mann DMA, Akiyama H, Hasegawa M (2013) Prion-like properties of pathological TDP-43 aggregates from diseased brains. Cell Rep 4:124-134. https://doi. org/10.1016/j.celrep.2013.06.007

45. Onozato T, Nakahara A, Suzuki-Kouyama E, Hineno A, Yasude T, Nakamura T, Yahikozawa H, Watanabe M, Kayanuma K, Makishita H, Ohara S, Hashimoto T, Higuchi K, Sakai T, Asano K, Hashimoto T, Kanno H, Nakayama J, Oyanagi K (2016) Axonal TDP-43 aggregates in sporadic amyotrophic lateral sclerosis. Neuropathol Appl Neurobiol 42:561-572. https://doi.org/10.1111/ nan. 12310

46. Paolicelli RC, Jawaid A, Henstridge CM, Valeri A, Merlini M, Robinson JL, Lee EB, Rose J, Appel S, Lee VM-Y, Trojanowski JQ, Spires-Jones T, Schulz PE, Rajendran L (2017) TDP-43 depletion in microglia promotes amyloid clearance but also induces synapse loss. Neuron 95:1-12. https://doi.org/10.1016/j.neuro n.2017.05.037

47. Peled S, Sade D, Bram Y, Porat Z, Kreiser T, Mimouni M, Lichtenstein A, Segal D, Gazit E (2017) Single cell imaging and quantification of TDP-43 and $\alpha$-synuclein intercellular propagation. Sci Rep 7:544. https://doi.org/10.1038/s41598-017-00657-z

48. Peri F, Nüsslein-Volhard C (2008) Live imaging of neuronal degradation by microglia reveals a role for v0-ATPase a1 in phagosomal fusion in vivo. Cell 133:916-927. https://doi.org/10.1016/j. cell.2008.04.037

49. Prajsnar TK, Cunliffe VT, Foster SJ, Renshaw SA (2008) A novel vertebrate model of Staphylococcus aureus infection reveals phagocyte-dependent resistance of zebrafish to non-host specialized pathogens. Cell Microbiol 10:2312-2325. https://doi.org/10 $.1111 / \mathrm{j} .1462-5822.2008 .01213 . x$

50. Rhodes J, Hagen A, Hsu K, Deng M, Liu TX, Look AT, Kanki JP (2005) Interplay of pu.1 and Gata1 determines myelo-erythroid progenitor cell fate in zebrafish. Dev Cell 8:97-108. https://doi. org/10.1016/j.devcel.2004.11.014

51. Richards B, Wolf E (1959) Electromagnetic diffraction in optical systems. II. Structure of the image field in an aplanatic system. Proc R Soc Lond A Math Phys Eng Sci 253:358-379

52. Rüb U, Vonsattel JPG, Heinsen H, Korf H-W (2015) Pathological nerve cell alterations in Huntington's disease (HD) and their possible role for the demise of nerve cells. In: Rüb U, Vonsattel JPG, Heinsen H, Korf H-W (eds) The neuropathology of Huntington's disease: classical findings, recent developments and correlation to functional neuroanatomy. Springer International Publishing, Cham, pp 119-123

53. Sage D, Donati L, Soulez F, Fortun D, Schmit G, Seitz A, Guiet R, Vonesch C, Unser M (2017) DeconvolutionLab2: an open-source software for deconvolution microscopy. Methods 115:28-41. https ://doi.org/10.1016/j.ymeth.2016.12.015
54. Sato T, Takeuchi S, Saito A, Ding W, Bamba H, Matsuura H, Hisa Y, Tooyama I, Urushitani M (2009) Axonal ligation induces transient redistribution of TDP-43 in brainstem motor neurons. Neuroscience 164:1565-1578. https://doi.org/10.1016/j.neuro science.2009.09.050

55. Sephton CF, Cenik C, Kucukural A, Dammer EB, Cenik B, Han Y, Dewey CM, Roth FP, Herz J, Peng J, Moore MJ, Yu G (2011) Identification of neuronal RNA targets of TDP-43-containing ribonucleoprotein complexes. J Biol Chem 286:1204-1215. https:// doi.org/10.1074/jbc.M110.190884

56. Shimonaka S, Nonaka T, Suzuki G, Hisanaga S, Hasegawa M (2016) Templated aggregation of TDP-43 by seeding with TDP43 peptide fibrils. J Biol Chem 291:8896-8907. https://doi. org/10.1074/jbc.M115.713552

57. Smethurst P, Newcombe J, Troakes C, Simone R, Chen Y-R, Patani R, Sidle K (2016) In vitro prion-like behaviour of TDP43 in ALS. Neurobiol Dis 96:236-247. https://doi.org/10.1016/j. nbd.2016.08.007

58. Spiller KJ, Cheung CJ, Restrepo CR, Kwong LK, Stieber AM, Trojanowski JQ, Lee VM-Y (2016) Selective motor neuron resistance and recovery in a new inducible mouse model of TDP-43 proteinopathy. J Neurosci 36:7707-7717. https://doi.org/10.1523/ JNEUROSCI.1457-16.2016

59. Spiller KJ, Restrepo CR, Khan T, Dominique MA, Fang TC, Canter RG, Roberts CJ, Miller KR, Ransohoff RM, Trojanowski JQ, Lee VM-Y (2018) Microglia-mediated recovery from ALSrelevant motor neuron degeneration in a mouse model of TDP-43 proteinopathy. Nat Neurosci 21:329. https://doi.org/10.1038/s4159 3-018-0083-7

60. Strom AR, Emelyanov AV, Mir M, Fyodorov DV, Darzacq X, Karpen GH (2017) Phase separation drives heterochromatin domain formation. Nature 547:241-245. https://doi.org/10.1038/ nature22989

61. Sumi H, Kato S, Mochimaru Y, Fujimura H, Etoh M, Sakoda S (2009) Nuclear TAR DNA binding protein 43 expression in spinal cord neurons correlates with the clinical course in amyotrophic lateral sclerosis. J Neuropathol Exp Neurol 68:37-47. https://doi. org/10.1097/NEN.0b013e3181919cb5

62. Svahn AJ, Graeber MB, Ellett F, Lieschke GJ, Rinkwitz S, Bennett MR, Becker TS (2013) Development of ramified microglia from early macrophages in the zebrafish optic tectum. Dev Neurobiol 73:60-71. https://doi.org/10.1002/dneu.22039

63. Walker AK, Spiller KJ, Ge G, Zheng A, Xu Y, Zhou M, Tripathy K, Kwong LK, Trojanowski JQ, Lee VM-Y (2015) Functional recovery in new mouse models of ALS/FTLD after clearance of pathological cytoplasmic TDP-43. Acta Neuropathol 130:643660. https://doi.org/10.1007/s00401-015-1460-x

64. Wang IF, Wu LS, Chang HY, Shen JCK (2008) TDP-43, the signature protein of FTLD-U, is a neuronal activity-responsive factor. J Neurochem 105:797-806. https://doi.org/10.111 1/j.1471-4159.2007.05190.x

65. Westerfield M (2000) The zebrafish book: a guide for the laboratory use of zebrafish (Danio rerio). University of Oregon Press, Eugene

66. Winton MJ, Igaz LM, Wong MM, Kwong LK, Trojanowski JQ, Lee VM-Y (2008) Disturbance of nuclear and cytoplasmic TAR DNA-binding protein (TDP-43) induces disease-like redistribution, sequestration, and aggregate formation. J Biol Chem 283:13302-13309. https://doi.org/10.1074/jbc.M800342200

67. Zeineddine R, Whiten DR, Farrawell NE, McAlary L, Hanspal MA, Kumita JR, Wilson MR, Yerbury JJ (2017) Flow cytometric measurement of the cellular propagation of TDP-43 aggregation. Prion 11:195-204. https://doi.org/10.1080/19336896.2017.13144 26 
68. Zelenchuk TA, Brusés JL (2011) In vivo labeling of zebrafish motor neurons using an mnx1 enhancer and Gal4/UAS. Genesis 49:546-554. https://doi.org/10.1002/dvg.20766

69. Zhang Y-J, Gendron TF, Xu Y-F, Ko L-W, Yen S-H, Petrucelli L (2010) Phosphorylation regulates proteasomal-mediated degradation and solubility of TAR DNA binding protein-43 C-terminal fragments. Mol Neurodegener 5:33. https://doi. org/10.1186/1750-1326-5-33
70. Zhu L, Brangwynne CP (2015) Nuclear bodies: the emerging biophysics of nucleoplasmic phases. Curr Opin Cell Biol 34:23-30. https://doi.org/10.1016/j.ceb.2015.04.003

71. Zhu L, Xu M, Yang M, Yang Y, Li Y, Deng J, Ruan L, Liu J, Du S, Liu X, Feng W, Fushimi K, Bigio EH, Mesulam M, Wang C, Wu JY (2014) An ALS-mutant TDP-43 neurotoxic peptide adopts an anti-parallel b-structure and induces TDP-43 redistribution. Hum Mol Genet 23:6863-6877. https://doi.org/10.1093/hmg/ddu409 